\title{
Towards Higher Educational M-Learning Platform for Conceptual STEAM Environment
}

\author{
Jinhong $\mathrm{Kim}^{1}$, DeugWhan $\mathrm{Sa}^{2}$ and Jong-Yun $\mathrm{Kim}^{3}$ \\ ${ }^{1}$ Department of Big Data, Sungkyunkwan University, \\ ${ }^{2}$ Department of Public Administration, Kyungdong University, \\ ${ }^{3}$ Department of Computer Engineering, Kyungdong University, \\ ${ }^{1}$ jinhkm@skku.edu, ${ }^{2}$ sdwhan@kduniv.ac.kr, ${ }^{3}$ kjyuni@kduniv.ac.kr
}

\begin{abstract}
Nowadays, the progress of information and communications techmology and information of society has made wire/wireless-based comminnications become a popular approach, being a widely used methodology for delivering various educatjonal programs and organizational business situations, such as continuous education, online academic lecture, distant private trainings in companies, and other similar cases. Graduate students and company employees are continuousty in need to learn more advanced knowledge, but oftentimes have limited opportumities due to time, location, and cost limitations involved in traditional learning. Distance education by means of a Mobile Learning Environment (MLE) is strongty requested tosolve these problems. Such systems could help in organizing a meeting comfortably via the network environment. This highly technological innovation is used tolink multipte users to join from any place to meet in a virtual environment. It also bring change ineducation-based communication by reducing the operational administrative costs and $\mathrm{Can}$ make educational content competition stronger. Occasionally the social, communication demand for internationalized educational program is continuously increasing. Hence, the role of universities is to change the direction of the leanning environment from the traditional classroom into wire/wireless based communtations for learning. Accordingly, these higher educational institutions ore expected to spearhead that change direction with distant learning, or distant lecture technologies. In this paper, we present the policy and target of higher educational models using STEAM.
\end{abstract}

Keywords: STEAM, Higher Education Model, Mobile Learning Environment

\section{Introduction}

Recent y, higher education and life-long human resource development are urgent issues in supporting the sustainable development of global society [1-3]. The conventional methods of education are not enough to support global demands because of limitations in technology, geographical location, and time zone-based resources. Therefore, a suitable use of advanced ICT in education is needed to meet these social demands, especially for developing countries where high-quality Internet service is not available and there is a prevalent lack of educational resources. It is well recognized that in the future, developing countries would play a key role in sustainable development more than before when opportunities on higher education were limited [4-6]. Therefore, a suitable use of advanced ICT in education is needed to meet the social demands, especially for developing countries where high-quality Internet service is not available and the prevalent lack of educational resources. It is well recognized that in the future developing countries would play a key role in sustainable development more than before where opportunities on higher education were limited. The features of $\mathrm{m}$-Communication for higher education should be also different from those of the undergraduate education. Based on the 
requirements and demands of higher education, the goals of this research are defined as follows: 1) To remove the obstacles of both time and place to post-secondary education for individuals and corporations by developing and demonstrating innovative, costeffective approaches in delivering education through the use of rapidly evolving advanced technology [7]. 2) To provide a means for learners to obtain formal recognition of the skills and knowledge obtained outside the traditional higher education context and/or from multiple providers through the assessment and certification of competency. 3) To encourage joint development of new learning and assessment materials among universities in the global scale, and technology standards that ensure connectivity. Trends and methodologies of $\mathrm{m}$-Learning service have been changing, and nowadays are virtual conference-based, so called video conferencing, or streaming-based contents are being sought out. The new technology brings courses alive by allowing online learners to use their visual and auditory senses. Authoring tools for virtual conference-based content is needed to support this new trend and methodology. The tool should give the opportunity to reuse contents or archives, which can be shared to learners. For m-Meeting service, stability of the meeting operation in the unreliable networkenvifonment is very important. To preserve the meeting operation, the system should perform automatic reconnection for intermittent network, especially in areas with tow-speed Internet) [8-10]. A lot of requirements from the business sector need to be addressed, e.g. content privacy and system management issues. In the m-Meeting section, a meeting management system for controlling member groups and contents were implemented. The author designed a simple new group-based structure for easier management. The system can manage the contents of each group by limiting the number of content, limiting the number of concurrent access, and controlling the behavior of logging-in members. The author also proposed the automatic reconnection network to belp the participants who use unreliable networks by preserving the quality of online donferencecoperation for the best distant meeting. After all, a usual computer with usual operating systems such as Windows, Linux and Mac operating systems is enough for use.

\section{M-Learning System for STEAM}

Distance ducation has been utilized to provide instructional access to adult students living in remote areas where traditional education is not available. An m-Learning system is a popular technology for distance education. The m-Learning education system is based on the web-oriented models conventional in-person education by providing equivalent virtual access to classes, contents, and other resources. It is also a social space where students and teachers can interact through threaded discussions or chat, as shown in Figure 1. There's's a variety of benefits in using the m-Learning system. A learner who has limitations of time and location can learn by themselves with the distant-learning system via Internet technology at a lower cost and higher quality in the global scale [11]. MLearning system can be integrated with a physical learning environment, which may be referred to as blended learning. It can take place synchronously or asynchronously. In synchronous systems, participants meet in "real-time" and teachers conduct live classes in virtual classrooms. Students can communicate through a microphone, chat rights, or by writing on the board. In asynchronous learning, which is sometimes called "self-virtual environment" learning, students are expected to complete lessons and assignments independently through the system. Asynchronous courses have deadlines just as synchronous courses do, but each student is learning at their own pace [12-15]. 


\section{M-Learning Platform for STEAM}

There are three main types of the m-Learning platform,G.e., the standalone system, the server-client system, and cloud computing system. A lot of applications are working as a standalone system. They do not need network infrastructure, but they do require installation of software applications in the user's computer. They provide almost full support for various operating systems [16]. Moreover, the implementation of the mLearning system on a cloud-computing platform has its peculiarities and needs a specific approach. This paper presents an m-Learning ecosystem based on cloud computing infrastructure. The benefits of this system are that it is reliable, flexible, and cost-efficient. The system also has mechanisms to guarantee teaching and learning activities, and the quality and the ruming of the ecosystem. In addition, this measured the positive impact of using cloud-computing architectures upon the m-Learning solution development [17]. The measured result shows that a cloud computing system can reduce the cost of infrastructure maintenance and risk of hardware failure of an m-Learning system, and Figure 2 below shows the m-Learningsystem workflow.

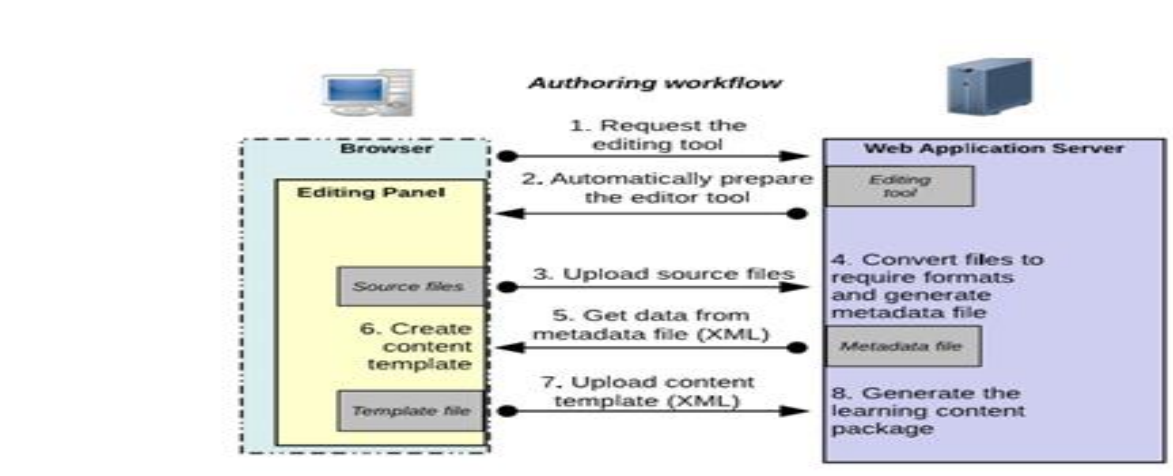

Figure 2. M-Learning System Workflow

\section{Wireless-Based Content of m-Learning for STEAM}

Learning contents are the essential element of an m-Learning system. The prevalent characteristics of learning content can be categorized in three groups: (1) General webbased learning content has been used as a standard e-learning system since web 
technology was first initiated. It uses standard HTML elements such as text, images, and links for making content. (2) Slide-based learning content is composed of slides with embedded objects, such as text, image, and others. Slide is the main element of the content. It is used to control the embedded object from changing. (3) Wireless-based learning content is proposed to integrate data stream and slide presentation into a learning content. The wireless-based stream is used as a baseline of a learning content. Presentation slides are automatically changed by operating time. In the educational system, the use of this for student learning has long been discussed since it consist of various multimedia types such as image, audio, animation, and teacher actions. This form of technology brings courses alive by allowing online learners to use their visual and auditory senses to learn new concepts [18-20]. This streaming allows online instructors the opportunity to deliver alternative course materials to learners who use m-Kearning system especially in higher education, and Figure 3 shows the data structure of the proposed wireless-based learning content package.

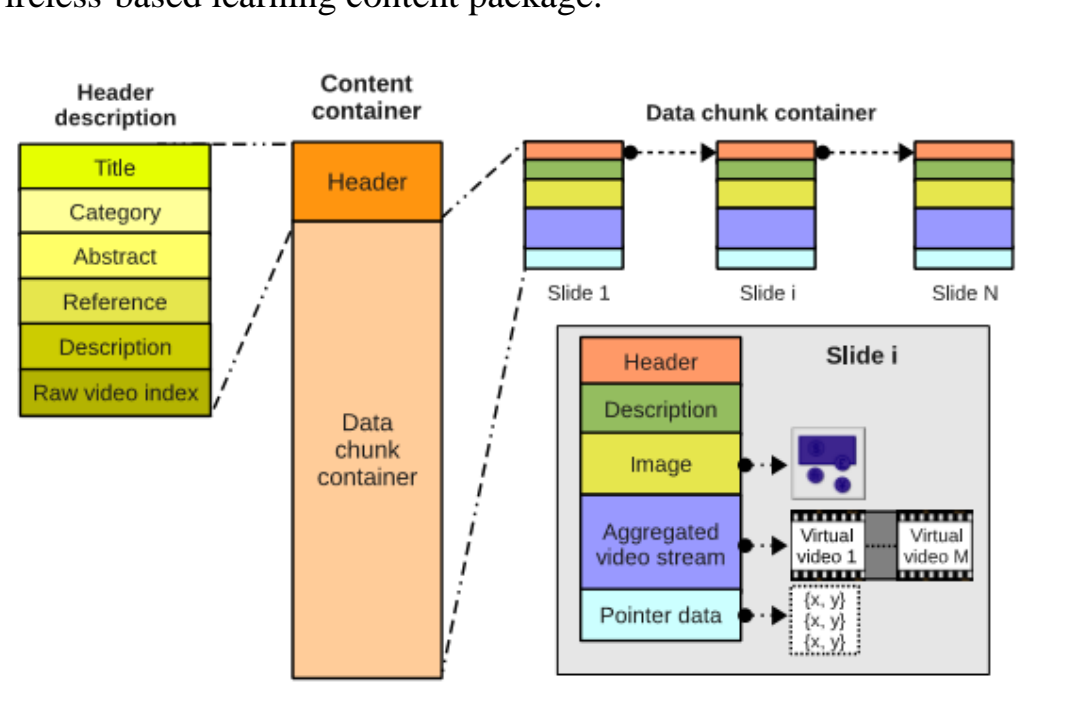

\section{Figure 3. Data Structure of M-Learning Content Page}

The content package consists of two segments, which are the header information and the slide chunk series of the presentation. The header segment is composed of six important fields. Ir contains the content general information such as title, category and subcategory, abstraet, reference, raw file reference, and description of content. In the slides chunk segment, each slide is an independent unit with five fields, which contains importantslide elements such as header, image, aggregated data stream, pointer data, and slide description. From the data structure, presentation slide is used as the baseline of content stream. Header information is key data used to reference other data chunks, making it flexible for rearranging the slide sequence that includes the whole data in a chunk. Image data is used for linking to an image file and pointer data also linked to a file that stores pointer action data [21-23]. Aggregated data are referred to the aggregated data stream wherein the virtual data clips are encapsulated. Slides data are stored into each file as separate data packages instead of one complete file. It is considered to be the best method for changing the meta-data file during editing and viewing operations, and Figure 4 shows a database schema for higher educational STEAM. 


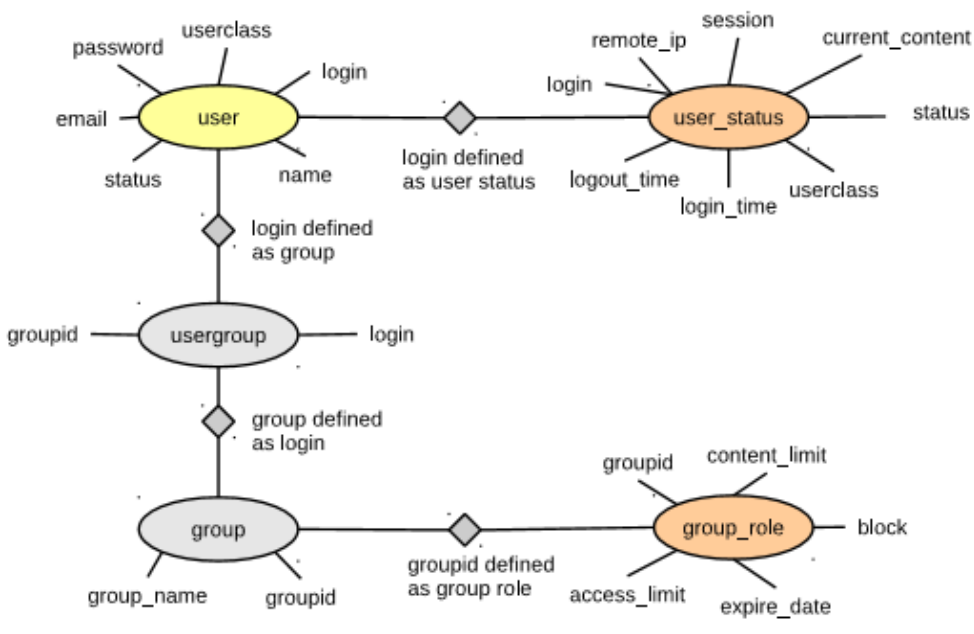

Figure 4. Database Schema for Higher Edudationar StEAM

\section{Conclusions}

The proposed authoring and viewing tools have exhibited numerous advantages as an $\mathrm{m}$-Learning tool for higher education. The total system can help accomplish the purposes of distance learning among universities at makes leaping activities available anytime and anywhere. In addition, cross-platform and clouid computing are supported to break the barriers in various operating systems, and application software installation is not necessary on the users' computer. Since using online content is fast becoming a popular a trend for obtaining knowledge due to the vastavailability of information and content from the Internet, then the proposed system can be used to support advanced knowledge by self-learning. It is considered to support classroom-based learning due to the increasing social demand internationally, and to address the limitations of traditional learning due to time, location, and cost. Therefore, the author implements a new online authoring tool for $\mathrm{m}$-Learning system using Flash technology. The proposed system is achieved and optimized to support cloud computing technology since this technology is implemented in a wide variety of archurectures, services, models, and other technologies for STEAM.

\section{Acknowledgments}

This research was financially supported by Kyungdong University.

\section{References}

[1] Y. Kolodner, P. J. Camp and D. Crismond, "Problem-based learning meets case-based reasoning in the middle-school science classroom: Putting learning by design into practice", Journal of the Learning Sciences, vol. 12, no. 4, (2001), pp. 495-547.

[2] Y. Georgette, "STEAM Education: an overview of creating a model of integrative education", Pupil's Attitudes Toward Technology, vol. 19; (2008), pp.335-358.

[3] K. Squire, "Changing the Game: What happens when video games enter the classroom", Innovate Journal of Online Education, vol. 1, no. 6, (2005).

[4] D. W. Shaffer, H. R. Squire and J. K. R. Gee, "Video games and the future of learning", WCER Working Paper, vol. 4, (2005).

[5] K. Squire, H. Jenkins, H. Walter and M. Heather, "Design Principles of Next-Generation Digital Gaming for Education", Educational Technology, vol. 43, no. 5, (2003), pp. 17-23.

[6] W. J. Hyun and E. Wohn, "The analysis on the effectiveness of afterschool program at elementary school", Foreign Language Education, vol. 21, no. 1, (2014), pp. 75-85.

[7] K. Engil and J. Kim, "STEAM education curriculum design on project based learning", Journal of Information Education, vol. 15, no. 4, (2011), pp. 551-560. 
[8] K. Jeongryel and Y. Chang, "The effect on MMORPG to the elementary school students", MultimediaAssisted Language Learning, vol. 11, no. 1, (2008), pp. 103-125.

[9] K. L. Beckett and D. W. Shaffer, "(in press). Augmented by reality: The pedagogical praxis of urban planning as a pathway to ecological thinking", Journal of Educational Computing Research.

[10] J. P. Gee, "(in press). What will a state of the art video game look like", Innovate.

[11] A. S. Gordon, "Authoring branching storylines for training applications. In Y. Kafai, W. A. Sandoval, N. Enyedy, A. S. Nixon \& F. Herrera (Eds.)", Proceedings of the Sixth International Conference of the Learning Sciences Mahwah, NJ: Erlbaum, pp. 230-238.

[12] R. Halverson, "Systems of practice: How leaders use artifacts to create professional community in schools", Education Policy Analysis Archives, vol. 11, no. 37, (2003).

[13] R. Halverson, "Accessing, documenting and communicating practical wisdom: The phronesis of school leadership practice", American Journal of Education, vol. 111, no. 1, (2004), pp. 90-121.

[14] R. Halverson and Y. Rah, "Representing leadership for social justice: The case of Franklin School", Under review by Journal of Cases in Educational Leadership, (2004).

[15] J. Lave and E. Wenger, "Situated learning: Legitimate peripheral participation", Cambridge, UK: Cambridge University Press, (1991).

[16] R. C. Schank, "Goal-based scenarios (Technical Report No. 36)", Evanston, LL: Northwestern University, the Institute for the Learning Sciences, (1992).

[17] R. C. Schank, "Virtual learning: A revolutionary approach to building adhighly skt1led workforce", New York: McGraw Hill, (1997).

[18] R. C. Schank, A. Fano, B. Bell and M. Jona, "The designef goal based scenarios", Journal of the Learning Sciences, vol. 3, (1994), pp. 305-345.

[19] D. W. Shaffer, "Learning mathematics through design: The anatomy of Escher's World", Journal of Mathematical Behavior, vol. 16, no. 2, (1997), pp. 95-112.

[20] D. W. Shaffer, "Epistemic frames and islands of expertise: Learning from infusion experiences", In Y. Kafai, W. A. Sandoval, N. Enyedy, A. S. Nixon, \& F. Herrera (Eds.), Proceedings of the Sixth International Conference of the Learning Sciences.Mahwah, NJ: Erlbaum, (2004), pp. 473-480.

[21] D. W. Shaffer, "Pedagogical praxis: The professions as models for post-industrial education", Teachers College Record, vol. 106, no. 7, (2004), pp. 1401-1421.

[22] D. W. Shaffer, "When computer-supported collaboration means computer-supported competition: Professional mediation as a módel for collaborative learning", Journal of Interactive Learning Research, vol. 15, no. 2, (2004), pp. 101-115.

[23] T. R. Sizer, "Horace's copmpromise: The dilemma of the American high school", Boston: Houghton Mifflin, (1984).

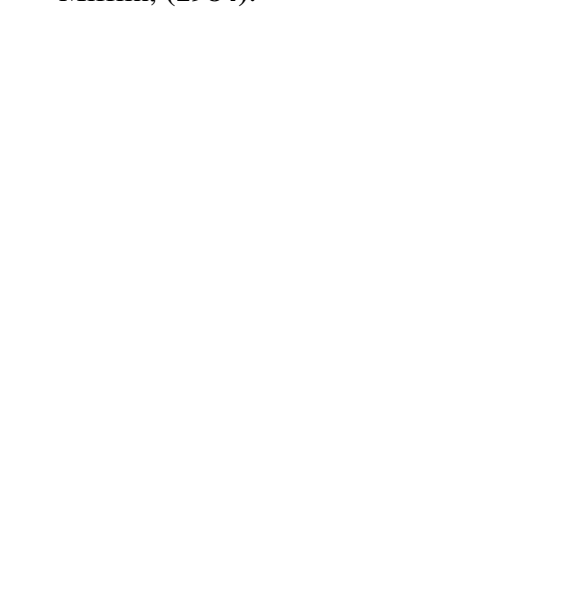

